\title{
Assisting Virtual Sessions with Spreadsheets in Chemical Engineering Education
}

\author{
Claudia Roman ${ }^{1}$, Yusuf Makarfi Isa ${ }^{2}$ and Moisés García-Morales ${ }^{3}$ \\ ${ }^{1,3}$ Departamento de Ingeniería Química, Escuela Técnica Superior de Ingeniería, Universidad de Huelva, 21071, \\ Huelva, Spain \\ ${ }^{2}$ Department of Chemical Engineering, Durban University of Technology, PO Box 1334, Durban, 4000, South \\ Africa
}

\begin{abstract}
Since the COVID19 outbreak, the normal development of the lectures has been considerably affected. Under this less engaging scenario of $100 \%$ virtual learning, teachers have felt compelled to readjust their methodology. In subjects with large loads of calculations, the use of spreadsheets can be a better option than using a drawing tablet for just presenting the problem results. Spreadsheets allow theoretical contents to be applied on specific exercises, thereby improving students' motivation. On these grounds, we report the use of Microsoft Excel built-in functions in Chemical Engineering core matters such as Mass/Energy Balances and Mass Transfer Separations. The experience was based on a collaboration at an international level between the Durban University of Technology (South Africa) and the University of Huelva (Spain). Conclusions were drawn on the creative use of Microsoft Excel built-in functions which yielded results that improved by far hand calculations and enabled to look into the effect of the main process variables.
\end{abstract}

Keywords: Virtual Learning, Chemical Engineering, Spreadsheets, Microsoft Excel 


\section{Introduction}

In Chemical Engineering study programs, the theoretical lectures have been traditionally supported by practical sessions where the teachers explain how to solve related numerical problems on a blackboard. The current unexpected scenario of $100 \%$ virtual learning has forced the instructors to readjust their methodology. Some teachers have just opted to present the calculations on a drawing tablet, which is nearly the same method they used in the classroom. Other teachers, instead, think that online lectures really require a more engaging approach. Given the distance learning situation, the established balance between theory and practice is probably no longer valid in terms of students' involvement. A committed teacher must, thus, design a balanced program of theoretical lectures and practical workshops. In that sense, Microsoft Excel may provide support to the study of the Chemical Engineering core matters. Fundamental concepts can be dealt with on specific worked out exercises, thereby making the classes more appealing.

Microsoft Excel has found extensive application in many Chemical Engineering matters: mass and energy balances (Misovich \& Biasca, 1990), process simulation and control (Nachtigalova et al., 2020), optimization (Iglesias \& Paniagua, 1999), chemical kinetics and reaction engineering (Chebbi, 2014), heat transfer and transport phenomena (Stammitti, 2013), phase equilibria and thermodynamics (Castier \& Amer, 2011), mechanical unit operations (Lenzi \& Lenzi, 2007) and mass transfer separation problems (Cardoso \& Tannous, 2020).

Microsoft Excel is part of Microsoft Office. Its availability and popularity make it ideal for distance learning (Kanyarusoke \& Uziak, 2011). Students can work from home on their own laptops guided by the teacher who delivers instructions through a videoconferencing platform such as Zoom or Microsoft Teams. Using Microsoft Excel during the practical sessions can change the students' perception on this software. Most students just use Microsoft Excel as a simple calculator. The challenge is to show them that Microsoft Excel can be of great interest to the study of core subjects such as Mass Transfer Unit Operations or Mass/Energy Balances.

The proposed study has arisen as a response to the teaching needs derived from the current sanitary crisis. The following goals were pursued:

- To engage the students during the online lectures.

- To instruct the students in the use of Microsoft Excel built-in functions.

- To develop information and communication technologies (ICT) skills related to the use of spreadsheets in engineering calculations (Coronell, 2005).

\section{Method}

In times of COVID19, both at the Durban University of Technology (South Africa) and the University of Huelva (Spain), Chemical Engineering teaching staff are taking advantage of the power of spreadsheets for teaching core subjects. We will herein focus on Mass Transfer Unit Operations and Mass/Energy balances. DUT and UHU are Erasmus+ KA107 partners.

Basically, the theoretical lectures were limited to the minimum strictly necessary to present the fundamental concepts. These were supported by practical workshops using Microsoft 
Excel. The methodology, which consisted in the use of simple built-in functions in specific case studies, empowered the students with skills to analyze and optimize the solution. Microsoft Excel built-in functions avoided the need for programming. Access to theoretical lectures and workshops was provided by Zoom and Microsoft Teams.

The strategy intended to reinforce the classical methodologies existing in Mass Transfer Separations and Mass/Energy Balances, from a transversal perspective based on the development of ICT competences. More specifically, the project must be seen as an attempt to promoting the so-called digital culture among Higher Education students through the use of spreadsheets in engineering calculations.

Upon using the above described method, conclusions have been jointly drawn by DUT and UHU lectures with regards to the implications on the students' learning as compared to the traditional classes.

\section{Results and Discussion}

The power of spreadsheets is of special interest in multistage separations as well as in chemical proceses involving reaction. We describe some key factors which need consideration so that the use of spreadsheet yields successful learning.

\subsection{Multicomponent separation using multistage distillation}

Multistage distillation is the heart of the petroleum, petrochemical, and chemical industries. Thus, understanding of its design and optimization is of great value to practicing engineers in the process industry. Most practical problems involve multicomponent mixtures. As compared to binary distillation, it is not possible to completely specify distillate and bottoms compositions in multicomponent distillation. This fact has a major impact on calculation procedures (Wankat, 2017). However, when either heavy non-key or light non-key components are not present, complex matrix methods are not necessary. Even so, the use of spreadsheets such as Microsoft Excel and its logical operators facilitate the implementation of stage-by-stage design methods that enable what-if analysis and, so, optimization.

Fig. 1 presents a Microsoft Excel worksheet with the preliminary calculations required to find the number of equilibrium stages in a distillation problem solved by the Lewis-Matheson method. A ternary mixture of hydrocarbons (butane, pentane and octane) was dealt with. This method is similar to the McCabe-Thiele method for binary distillation, thus it is based on the assumption of constant molal overflow. The parameters for the calculation of vapor-liquid equilibrium (VLE) data are provided as described in Wankat (2017). The light and heavy key components recoveries, $r_{\mathrm{c} 5, \mathrm{D}}$ and $r_{\mathrm{c} 8, \mathrm{C}}$, respectively, are used to solve the external mass balances. The reflux ratio, RR, and feed liquid fraction, $\mathrm{q}$, are used to find the vapor and liquid molar flow rates at the column. Finally, distillate and bottoms composition and V-L molar flow rates are used to determine the rectifying and stripping operating lines. 
3rdInternational Conference on Applied Research in

EDUCATION

04-06 June,2021

Barcelona, Spain

Figure 1: Preliminary calculations for a multistage distillation problem by the Lewis-Matheson method for a ternary mixture (c4, c5 and $c 8)$

\begin{tabular}{|c|c|c|c|c|c|c|c|c|c|c|c|c|}
\hline \multirow[b]{2}{*}{ V } & A & B & C & D & $\mathrm{E}$ & $\mathrm{F}$ & G & $\mathrm{H}$ & 1 & $\mathrm{~J}$ & K & L \\
\hline & \multicolumn{5}{|c|}{ VLE parameters and feed compositions: } & & & \multicolumn{2}{|c|}{ Problem data: } & & & \\
\hline & & $a_{\mathrm{T} 1}$ & $a_{\mathrm{T} 2}$ & $a_{\mathrm{T} 6}$ & $a_{p}$ & $x_{F}$ & & $F=$ & 10000 & $\mathrm{kmol} / \mathrm{h}$ & & \\
\hline & c4: & -1280557 & 0 & 7.94986 & -3.248 & 0.15 & & $r_{c 5, D}=$ & 0.99 & & & \\
\hline & c5: & -1524891 & 0 & 7.33129 & -3.002 & 0.25 & & $r_{C B, B}=$ & 0.98 & & & \\
\hline & c8: & 0 & -7646.82 & 12.48457 & -2.463 & 0.6 & & $\mathrm{RR}=$ & 1 & & & \\
\hline & & & & & & & & $q=$ & 1 & & & \\
\hline \multicolumn{3}{|c|}{ Mass balances: } & & & & & & & & & & \\
\hline & & $x_{D}$ & $\mathrm{x}_{\mathrm{B}}$ & & & & & & & & & \\
\hline 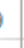 & c4: & 0.366 & 0.000 & $D=$ & 4095 & $\mathrm{kmol} / \mathrm{h}$ & & & \multicolumn{2}{|c|}{ Operating lines: } & & \\
\hline 0 & c5: & 0.604 & 0.004 & $B=$ & 5905 & $\mathrm{kmol} / \mathrm{h}$ & & & \multicolumn{2}{|c|}{ Rectifying } & \multicolumn{2}{|c|}{ Stripping } \\
\hline 1 & c8: & 0.029 & 0.996 & & & & & & slope & intercept & slope & intercept \\
\hline 2 & & & 1 & & & & & c4: & 0.500 & 0.183 & 1.721 & 0.000 \\
\hline \multicolumn{4}{|c|}{ L and V molar flow rates: } & & & & & c5: & 0.500 & 0.302 & 1.721 & -0.003 \\
\hline 4 & & & & & & & & c8: & 0.500 & 0.015 & 1.721 & -0.718 \\
\hline 5 & $\mathrm{~L}=$ & 4095 & $\mathrm{kmol} / \mathrm{h}$ & $V=$ & 8190 & $\mathrm{kmol} / \mathrm{h}$ & & & & & & \\
\hline & $L^{\prime}=$ & 14095 & $\mathrm{kmol} / \mathrm{h}$ & $V^{\prime}=$ & 8190 & $\mathrm{kmol} / \mathrm{h}$ & & & & & & \\
\hline
\end{tabular}

More interestingly, Fig. 2 illustrates the solution of the above problem. Using the IF operator, decisions can be made in virtue of whether one or more conditions are met. The advantage is that full automation of the solving algorithm is feasible. For example, through the formula in cell G27, =IF(AND(F26<C $\$ 10 ; \mathrm{F} 27>\mathrm{C} \$ 11)$;"stop";"continue"), the algorithm will tell us to continue stepping off stages until two conditions are met simultaneously: i) $\mathrm{x}_{\mathrm{c} 5, \mathrm{n}}$ $\leq \mathrm{x}_{\mathrm{c} 5, \mathrm{C}}$; and ii) $\mathrm{x}_{\mathrm{c} 8, \mathrm{n}} \geq \mathrm{x}_{\mathrm{c} 8, \mathrm{C}}$. It can be observed that stage 6 fulfils both conditions. In a similar way the IF operator can be used to decide whether vapor compositions in cells C25 to C27 have to be calculated using the rectifying or the stripping operating line. For example, the formula in cell $\mathrm{C} 25$ is $=\mathrm{IF}(\mathrm{F} 26 / \mathrm{F} 27>\mathrm{E} \$ 18 ; \mathrm{I} \$ 12 * \mathrm{~F} 25+\mathrm{J} \$ 12 ; \mathrm{K} \$ 12 * \mathrm{~F} 25+\mathrm{L} \$ 12)$. The criterion in cell E18 that provides the optimum feed location can be found elsewhere (Wankat, 2017). The method, thus, may bridge the always existing gap between hand calculations, typical from the traditional lectures, and the use of process simulators in Chemical Engineering study programs (Hinestroza \& Papadopoulos, 2003). 
Figure 2: Solution to the above problem

\begin{tabular}{|c|c|c|c|c|c|c|c|c|}
\hline$\Delta$ & $\mathrm{A}$ & $\mathrm{B}$ & C & $\mathrm{D}$ & $\mathrm{E}$ & $\mathrm{F}$ & $\mathbf{G}$ & $\mathrm{H}$ \\
\hline 18 & & & & Feed loc. crit.= & 0.41667 & & & \\
\hline \multicolumn{9}{|l|}{19} \\
\hline 20 & & & & Condenser_o & & & & \multirow[b]{2}{*}{ Solver } \\
\hline 21 & & $\mathrm{y}_{\triangle 4,1}=$ & 0.366 & & $x_{C 4,0}=$ & 0.366 & & \\
\hline 22 & & $\mathrm{Y}_{5,1}=$ & 0.604 & & $x_{5,0}=$ & 0.604 & & \\
\hline 23 & & $\mathrm{y}_{\mathrm{CB,1}, 1}=$ & 0.029 & & $x_{C B, 0}=$ & 0.029 & & \\
\hline 24 & & & & Stage_1 & & & \multicolumn{2}{|c|}{ criterion: } \\
\hline 25 & & $\mathrm{y}_{\triangle 4,2}=$ & 0.237 & 63.79 & $x_{C 4,1}=$ & 0.108 & & \\
\hline 26 & & $\mathrm{y}_{5,2}=$ & 0.554 & ${ }^{\circ} \mathrm{C}$ & $x_{5,1}=$ & 0.503 & Rect & 1.292 \\
\hline 27 & & $\mathrm{y}_{\mathrm{CB}, 2}=$ & 0.209 & 1.000 & $x_{\mathrm{CB}, 1}=$ & 0.389 & continue & \\
\hline 28 & \multicolumn{3}{|c|}{ Optimum feed stage } & Stage_2 & & & & \\
\hline 29 & & $\mathrm{y}_{\mathrm{c}, 3}=$ & 0.061 & 102.46 & $x_{C 4,2}=$ & 0.035 & & \\
\hline 30 & & $\mathrm{y}_{5,3}=$ & 0.350 & ${ }^{\circ} \mathrm{C}$ & $\mathrm{x}_{\mathrm{E}, 2,2}=$ & 0.205 & Strip & 0.270 \\
\hline 31 & & $\mathrm{y}_{\mathrm{CB}, 3}=$ & 0.589 & 1.000 & $\mathrm{x}_{\mathrm{CB}, 2}=$ & 0.759 & continue & \\
\hline 32 & & & & Stage_3 & & & & \\
\hline 33 & & $\mathrm{y}_{\subset 4,4}=$ & 0.010 & 132.99 & $x_{\mathrm{C} 4,3}=$ & 0.006 & & \\
\hline 34 & & $\mathrm{y}_{5,4}=$ & 0.135 & ${ }^{\circ} \mathrm{C}$ & $x_{5,3,3}=$ & 0.080 & Strip & 0.088 \\
\hline 35 & & $\mathrm{Y}_{C B, 4}=$ & 0.854 & 0.999 & $x_{C B, 3}=$ & 0.913 & continue & \\
\hline 36 & & & & Stage_4 & & & & \\
\hline 37 & & $\mathrm{Y}_{04,5}=$ & 0.002 & 145.27 & $x_{C 4,4}=$ & 0.001 & & \\
\hline 38 & & $\mathrm{y}_{5,5}=$ & 0.042 & ${ }^{\circ} \mathrm{C}$ & $x_{5,4}=$ & 0.026 & Strip & 0.027 \\
\hline 39 & & $\mathrm{y}_{\mathrm{CB}, 5}=$ & 0.958 & 1.001 & $x_{C B, 4}=$ & 0.974 & continue & \\
\hline 40 & & & & Stage_5 & & & & $\mathrm{x}_{\mathrm{B}}$ \\
\hline 41 & & $\mathrm{Y}_{\triangle 4,6}=$ & 0.000 & 149.29 & $x_{C 4,5}=$ & 0.000 & & 0.000 \\
\hline 42 & & $\mathrm{Y}_{5,6}=$ & 0.010 & ${ }^{\circ} \mathrm{C}$ & $x_{5,5,5}=$ & 0.008 & Strip & 0.004 \\
\hline 43 & & $\mathrm{Y}_{C B, 6}=$ & 0.989 & 1.000 & $x_{C B, 5}=$ & 0.992 & continue & 0.996 \\
\hline 44 & & & & Reboiler_6 & & & & $\mathrm{x}_{\mathrm{B}}$ \\
\hline 45 & & & & 150.39 & $x_{\subset 4,6}=$ & 0.000 & & 0.000 \\
\hline 46 & & & & ${ }^{\circ} \mathrm{C}$ & $x_{5,6}=$ & 0.002 & Strip & 0.004 \\
\hline 47 & & & & 1.000 & $x_{C 8,6}=$ & 0.998 & stop & 0.996 \\
\hline
\end{tabular}

Moreover, the combined use of relative and absolute references makes it easy to repeat the same calculations with varying and fixed input values, thus facilitating the design of equilibrium-staged operations. Note that the same calculations between lines 25-27 (stage 1) are used in successive stages. Another feature that is worth mentioning is the special PASTE function, as the student might need to paste values, formulas or links. Finally, at every stage, VLE calculations are done. The students need first to find the stage temperature by solving a non-linear algebraic equation (bubble point at the column pressure). The GOAL SEEK function facilitates the process. However, Microsoft Excel does not recalculate the manipulated variable (stage temperature) upon changing the column conditions ( $q$, RR, recoveries, etc.). Thus, with a view to a what-if analysis, the SOLVER button in Fig. 2 is used to execute a macro which finds the whole temperature profile at the multistage distillation 
column. In stage 1, for example, the target is finding the temperature in cell D25 which yields a value of 1 in cell D27, =SUM(F25:F27).

\subsection{Material balances for processes involving reaction}

Material and Energy balances are among the fundamental knowledge areas that a Chemical Engineer should understand very well. Chemical Plant designs cannot be successfully executed without a good material and energy balance. Chemical Engineering students were required to design a calculator that could be used in determining the composition of various reagents involved in a reaction between carbon dioxide and hydrogen to produce methanol (Eq. 1). In another task, the learners were given a task to determine the energy involved in heating a binary mixture from 0 to 400 degrees Celsius. To allow for more creativity, all learners had different combination of numerical values in the given question.

Interestingly enough, learners came up with various interesting approaches towards solving the problems, there were students who developed macros to solve their problems while others used built in functions for calculations. Students made use of logical functions to make decisions especially where calculations were very much dependent on decision makings.

$$
\mathrm{CO}_{2}+3 \mathrm{H}_{2} \rightarrow \mathrm{CH}_{3} \mathrm{OH}+\mathrm{H}_{2} \mathrm{O}
$$

\section{Conclusions}

The experience allowed us to conclude that, if used creatively, the combination of Microsoft Excel built-in functions yields excellent results. If compared to hand calculations, Microsoft Excel helped improve the students' academic performance. Moreover, unlike process simulators, the Microsoft Excel designs carried out by our students still allowed them to perceive the essential steps of the design process. As the students progressed through the course, they got more involved and realized that Microsoft Excel built-in functions enable very professional results with little effort, thus being a practical tool for engineers. Some of the common mistakes made by the students in this type of problems, such as solving nonlinear equations or equations systems were minimized. In addition, the opportunity to assess individual understanding based on individually tailored problems allowed for better interaction between the instructors and learners that require further assistance. It is evident that these skills will allow Chemical engineers to be ready for the Industrial Revolution IR 4.0 .

\section{Acknowledgments}

The authors acknowledge Vicerrectorado de Investigación y Transferencia (Universidad de Huelva) for funding their contribution to $3^{\text {rd }}$ International Conference on Applied Research in Education. Moisés García Morales is also grateful to XXI Convocatoria de Proyectos de Innovación Docente (Vicerrectorado de Innovación y Empleabilidad, UHU) and Proyecto Piloto de Intercambios Virtuales para la Docencia (Vicerrectorado de Internacionalización, $\mathrm{UHU}$ ) for their support. 


\section{References}

Cardoso, J. P. M. and Tannous, K. (2020). Development of a computational tool for designing multicomponent distillation columns, Computer Applications in Engineering Education, vol. 28(4), pp. 908-922.

Castier, M. and Amer. M. M. (2011). XSEOS: An evolving tool for teaching chemical engineering thermodynamics, Education for Chemical Engineers, vol. 6(2), pp. 62-70.

Chebbi, R. (2014). Chemical Reactors Sequencing, Computer Applications in Engineering Education, vol. 22(2), pp. 195-199.

Coronell, D. G. (2005). Computer Science or Spreadsheet Engineering? An Excel/VBABased Programming and Problem Solving Course, Chemical Engineering Education, vol. 39(2), pp. 142-145.

Hinestroza, J. P. and Papadopoulos, K. (2003). Using spreadsheets and visual basic applications as teaching aids for a unit operations course, Chemical Engineering Education, vol. 37(4), pp. 316-320.

Iglesias, O. A. and Paniagua, C. N. (1999). Use of Spreadsheets in Optimization Problems Involving Iterations, Computer Applications in Engineering Education, vol.7(4), pp. 227-234.

Kanyarusoke, K. E. and Uziak, J. (2011). Spreadsheets: The Ideal Tool for Distance Learning in Engineering Education, Computer Applications in Engineering Education, vol. 19(2), pp. 216-223.

Lenzi, M.K. and Lenzi. E.K. (2007). Spreadsheet for Cyclone and Hydrocyclone Design Considering Nonspherical Particle Geometry, Computer Applications in Engineering Education, vol. 15(2), pp. 134-142.

Misovich, M. and Biasca, K. (1990). The power of spreadsheets in a mass and energy balances course, Chemical Engineering Education, vol. 25(1), pp. 46-49, 52.

Nachtigalova, I., Finkeova, J., Krbcova, Z. and Souskova, H. (2020). A spreadsheet- based tool for education of chemical process simulation and control fundamentals, Computer Applications in Engineering Education, vol. 28(4), pp. 923-937.

Stammitti, A. (2013). Spreadsheets for assisting Transport Phenomena Laboratory experiences, Education for Chemical Engineers, vol. 8(2), pp. 58-71.

Wankat, P. C. (2017). Separation Process Engineering, Includes Mass Transfer Analysis, 4th ed. New York city, NY: Prentice Hall. 